\title{
A rare case of leiomyoma of uterus with cystic degeneration
}

\section{Soumya Ranjan Panda*, Charu Chandra}

Department of Obstetrics \& Gynecology, AIIMS, Jodhpur, Rajasthan, India

Received: 11 March 2015

Accepted: 19 April 2015

\section{*Correspondence:}

Dr. Soumya Ranjan Panda,

E-mail: drsome4141@gmail.com

Copyright: (C) the author(s), publisher and licensee Medip Academy. This is an open-access article distributed under the terms of the Creative Commons Attribution Non-Commercial License, which permits unrestricted non-commercial use, distribution, and reproduction in any medium, provided the original work is properly cited.

\begin{abstract}
Leiomyoma of the uterus is the most common tumor of the female pelvis. The size of leiomyomas varies from microscopic to giant. Giant myomas are exceedingly rare. Here, we present a case of a woman with uterine myoma that had undergone cystic degenerative changes, mimicking an ovarian malignancy. It provided a lot of diagnostic challenge as even ultrasonography and CT scan were not confirmatory. Finally laparotomy was done keeping everything ready for the management ovarian malignancy. On laparotomy the mass was found to be leiomyoma of uterus with cystic degeneration.
\end{abstract}

Keywords: Leiomyoma, Cystic degeneration

\section{INTRODUCTION}

Leiomyoma of the uterus is the most common tumor of the female pelvis, which arises from uterine smooth muscle. Such tumors are found in nearly half of women over age 35 ; the prevalence increases during reproductive age and decreases after menopause. The estimated incidence is $20 \%-40 \%$ in women during their reproductive years. ${ }^{1-4}$ The size of leiomyomas varies from microscopic to giant. Giant myomas are exceedingly rare. $^{5}$ Appropriate surgical management and careful perioperative care are necessary to obtain a good result after removal. ${ }^{6}$ Here, we present a case of a woman with uterine myoma that had undergone cystic degenerative changes, mimicking an ovarian malignancy.

\section{CASE REPORT}

Patient Dhapu Devi 32 year Hindu female from Guda, Jodhpur, presented with chief complaints of heavy menstrual bleeding for 3 months, heaviness in lower abdomen for 1 month.

She was apparently alright 3 months back. To start with she developed increased flow during menstruation, associated with clots \& not associated with pain lower abdomen. There was heaviness in lower abdomen for last 1 month.

M/H - Previous Menstrual Cycles 5/30 days, avg. flow.

For last 3 months 8/30 days, increased flow, associated with clots.

LMP - 10 days back.

O/H - P3003, LCB- 4 Year back, using barrier method of contraception.

$\mathrm{P} / \mathrm{H}$ - She was not a known case of hypertension, diabetes or any other chronic diseases.

F/H - No family history of malignancies.

O/E - GC fair, mild pallor.

P/A - A well-defined globular mass in hypogastrium, 16 week size, soft, lower limit could not made out.

P/S- CX, vagina healthy, ant vaginal wall bulging. 
$\mathrm{P} / \mathrm{V}$ - A mass of variegated consistency predominantly cystic occupying the anterior fornix palpated, uterus could not be felt separately from the mass.

D/D - 1) Fibroid with degenerative changes 2) Adnexal mass

Consequently ultrasonography was done to differentiate the origin of mass. The results of routine laboratory testing including a complete blood count, serum electrolyte levels, tests of liver and renal function and Pap smear were normal.

Ultrasonography of pelvis showed mass with solid \& cystic components S/O malignant ovarian mass.

Her CA 125 \& CEA were within normal limits, but Ca 19-9 was 81 (increased).

As the clinical findings \& ultrasonographic findings were not correlated CT scan of abdomen \& pelvis was done.

On CT scan uterus was not separately seen, no E/O ascites. Large well defined thick wall cystic hypodense mass lesion in midline pelvis with internal enhancing soft tissue contents as described, likely represent neoplastic lesion of ?uterine origin, less likely ovarian etiology.

Laparotomy was planned keeping everything ready for the management of ovarian malignancy. On opening the abdomen a large 16 week size uterine mass was found. Bilateral ovaries and fallopian tubes were healthy. On cut section straw coloured fluids came out S/O cystic changes.

Specimen was sent for histopathologic examination. Histopathology revealed leiomyoma with cystic changes. Post-operative period was uneventful patient discharged on $7^{\text {th }}$ post-operative day after removal of stitches.

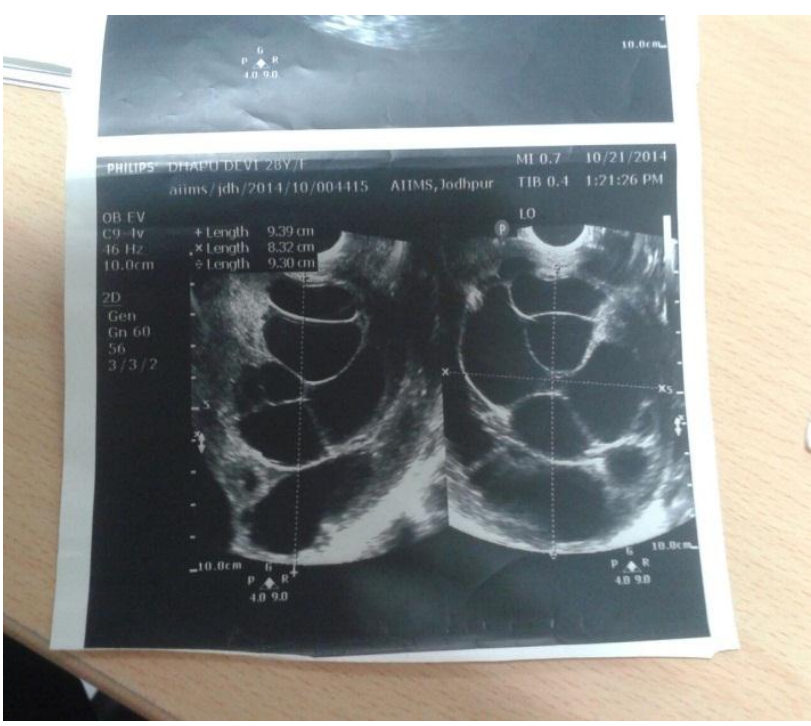

Figure 1: Ultrasonographic picture showing the mass.

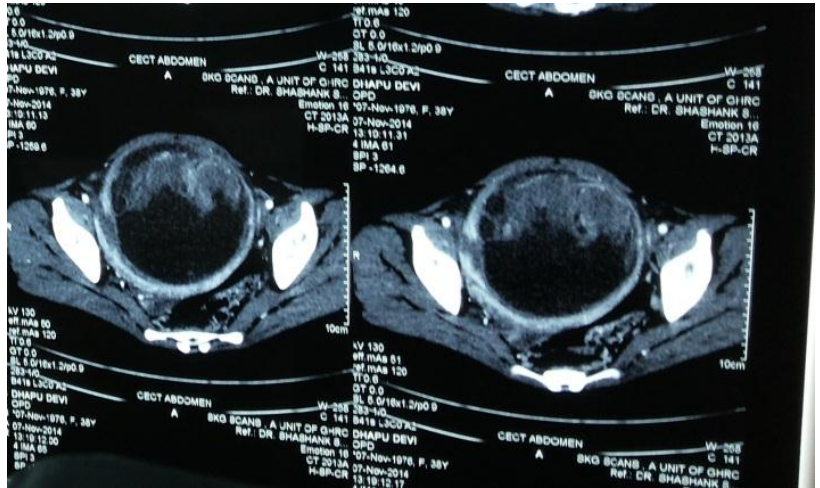

Figure 2: CT scan picture showing the mass.

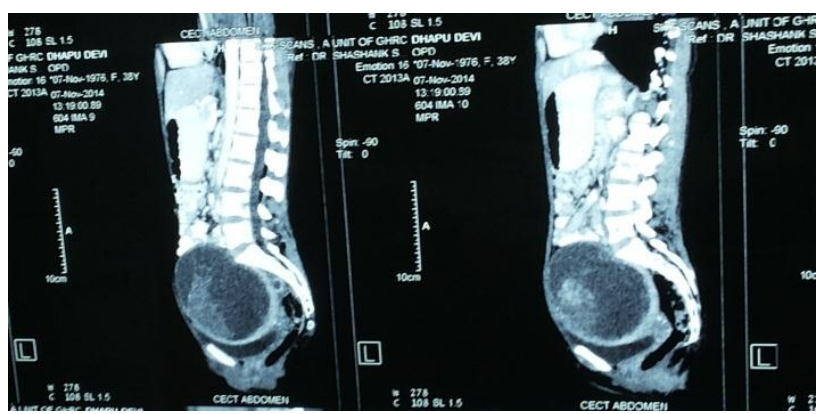

Figure 3: CT scan picture showing the mass.

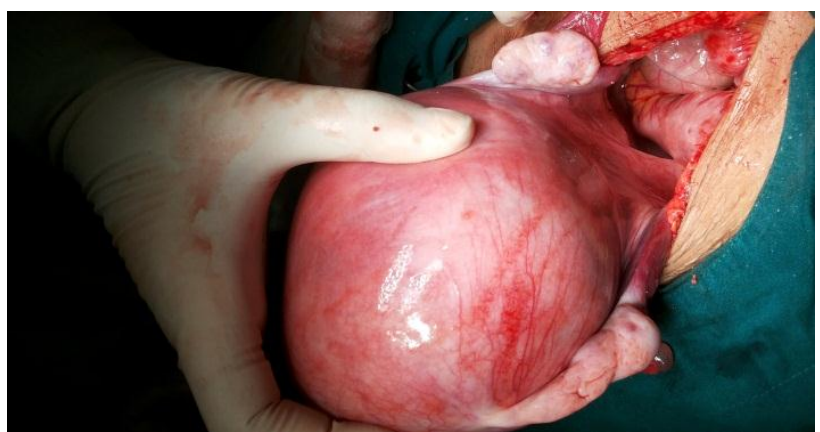

Figure 4: Picture at laparotomy showing fibroid uterus with bilateral healthy ovaries.

\section{DISCUSSION}

Large uterine fibroids can cause pain, constipation, increased frequency of micturition and menstrual bleeding. They can also affect reproduction by causing infertility, miscarriage and/or premature labor. ${ }^{1,2,5}$ As leiomyomas enlarge, they can outgrow their blood supply, resulting in various types of degeneration, such as hyaline, cystic, myxoid or red degeneration and dystrophic calcification. ${ }^{8}$ Hyalinization is the most common type of degeneration, occurring in up to $60 \%$ of cases. Cystic degeneration, observed in about $4 \%$ of leiomyomas, may be considered extreme sequelae of edema. ${ }^{9}$

Only few cases of giant uterine tumors have been reported in the recent literature. The largest uterine fibroid ever reported weighed $63.3 \mathrm{~kg}$ and was removed 
postmortem in $1888 .{ }^{10}$ The potential for uterine leiomyomas to grow to an extreme size before causing symptoms is quite remarkable. This is likely due to the relatively large volume of the abdominal cavity, the distensibility of the abdominal wall and the slow growth rate of these tumors.

Typical appearances of leiomyomas are easily recognized on imaging. However, the atypical appearances that follow degenerative changes can cause confusion in diagnosis. Leiomyomas have been misdiagnosed as adenomyosis, hematometra, uterine sarcoma and ovarian masses.

The preferred imaging modality for the initial evaluation is ultrasonography because it is the least invasive and the most cost-effective. ${ }^{11}$ The relative echogenicity of leiomyomas depends on the ratio of fibrous tissue to smooth muscle, the extent of degeneration and the presence of dystrophic calcification. ${ }^{12} \mathrm{~A}$ CT scan can be useful; however, leiomyomas are indistinguishable from healthy myometrium unless they are calcified or necrotic. MRI can define the anatomy of the uterus and ovaries, but availability and high cost are serious limitations. ${ }^{13}$

The current established management of uterine fibroids may involve one of the following approaches or a combination thereof: expectant management, surgical management, medical management or uterine artery embolization. The chosen approach should be individualized depending on various factors, including age, type and severity of symptoms, suspicion of malignancy, desire for future fertility and proximity to menopause. A surgical approach is most frequently preferred for management of giant leiomyomas.

\section{CONCLUSION}

Although fibroids typically have a characteristic USG appearance, degenerating fibroids can have variable patterns and pose diagnostic challenges. In such cases a CT scan or MRI can help in diagnosis. This case represents an unusual case of a leiomyoma with cystic degeneration masquerading as an ovarian mass in USG pictures. Pedunculated leiomyomas should be considered in the differential diagnosis of a multilocular and predominantly cystic adnexal mass. Sometimes the confusion is so much that the clear picture is revealed only at laparotomy.
Funding: No funding sources Conflict of interest: None declared

Ethical approval: Not required

\section{REFERENCES}

1. Hoffman B. Pelvic mass. In: Schorge J, eds. Williams Gynecology. 1st ed. New York: McGrawHill Companies; 2008: 197-224.

2. Courbiere B, Carcopino X. Fibromes uterins. In: Courbiere B, Carcopino X, eds. Gynecologie Obstetrique. 1st ed. Paris: Vernazobres-Greco; 20062007: 359-365.

3. Ryan GL, Syrop CH, Van Voorhis BJ. Role, epidemiology, and natural history of benign uterine mass lesions. Clin Obstet Gynecol. 2005;48:312-24.

4. Wallach EE, Vlahos NF. Uterine myomas: an overview of development, clinical features, and management. Obstet Gynecol. 2004;104:393-406.

5. Jonas HS, Masterson B. Giant uterine tumors. Obstet Gynecol. 1977;50:2s-4s.

6. Inaba F, Maekawa I, Inaba N. Giant myomas of the uterus. Int J Gynaecol Obstet. 2005;88:325-6.

7. Sabry M, Al-Hendy A. Innovative oral treatments of uterine leiomyoma. Obstet Gynecol Int. 2012;2012:943635.

8. Preayson RA, Hart WR. Pathologic considerations of uterine smooth muscle tumors. Obstet Gynecol Clin North Am. 1995;22:637-57.

9. Mayer DP, Shipilov V. Ultrasonography and magnetic resonance imaging of uterine fibroids. Obstet Gynecol Clin North Am. 1995;22:667-725.

10. Evans AT III, Pratt JH. A giant fibroid uterus. Obstet Gynecol. 1979;54:385-6.

11. Levens ED, Wesley R, Premkumar A, Blocker W, Nieman LK. Magnetic resonance imaging and transvaginal ultrasound for determining fibroid burden: implications for research and clinical care. Am J Obstet Genecol. 2009;200(5):537.e1-7.

12. Wladimiroff J. Uterine fibroids. In: Wladimiroff $\mathbf{J}$, eds. Ultrasound in Obstetrics and Gynaecology. 2nd ed. US: Elsevier; 2009: 303-306.

13. Asillas J, Joseph RC, Guerra JJ Jr. CT appearance of uterine leiomyomas. Radiographics. 1990;10:9991007

DOI: $10.18203 / 2320-1770 . i j r \operatorname{cog} 20150111$

Cite this article as: Panda SR, Chandra C. A rare case of leiomyoma of uterus with cystic degeneration. Int $\mathbf{J}$ Reprod Contracept Obstet Gynecol 2015;4:863-5. 